\title{
O QUE É UM ÍNDICE [[CONTEMPORÂNEO]]?'1
}

\author{
WHAT IS A [[CONTEMPORARY]] INDEX?
}

Silvana Drumond Monteiro²

Maria Júlia Carneiro Giraldes ${ }^{3}$

\begin{abstract}
RESUMO
Indices são paratextos, isto é, textos suplementares e de natureza epistêmica diferente dos textos que indexam, mas estritamente relacionados a eles. São importantes ferramentas de organização e recuperação da informação. Ao longo da História estão associados à concepção bibliográfica, ou seja, aos livros. No entanto, sua etimologia e sua pragmática remetem ao conceito anterior semiótico de indicar, apontar ou dar a direção. A partir dessa visão retrospectiva a questão de pesquisa é: 0 que é um índice contemporâneo? Especialmente um índice de busca, gerado por um mecanismo de busca por meio de uma solicitação ou pesquisa. Diante do objetivo de conhecer a estrutura de um índice contemporâneo, baseado no Google, que é gerado em uma SERP (Search Engine Results Page), buscou-se a análise de sua anatomia, a saber, os elementos constitutivos de sua estrutura, de acordo com Morville e Callender (2010), por meio de uma análise documental, como método, e ao mesmo tempo identificar, a partir da pesquisa documental, a estrutura básica de um índice no clássico ensaio de Wheatley (1879), com o título What is an index? Após o cotejamento desses índices, observou-se que sua estrutura básica modificou-se, dada a natureza performativa do substrato digital que os suporta, apresentando mais elementos, ao mesmo tempo em que reforçam seu aspecto semiótico indicial de ligação. Eles são, hoje, as nossas bússolas informacionais.
\end{abstract}

Palavras-chave: Índice. SERP. Google. Mecanismo de Busca.

\section{ABSTRACT}

Indexes are paratexts, that is, supplementary texts and of an epistemic nature different from the texts they index, but strictly related to them. They are important tools for organizing and retrieving information. Throughout history they are associated with the documentary conception, that is, with books. However, its etymology and its pragmatics refer to the previous semiotic concept of indicating, pointing or giving direction. From this retrospective view the research question is: what is a contemporary index? It is especially a search index, generated by a search engine through a request or search. In view of the objective of knowing the structure of a contemporary index, based on the Google search, that is generated in a Search Engine Results Page (SERP), we sought the analysis of its anatomy, that is, the constituent elements of its structure, according to Morville and Callender (2010), through a documentary analysis as a method, and the identification, from documentary research, of the basic structure of an index in Wheatley's classic essay (1879) entitled What is an index?. After the comparison of these indices, it was observed that their basic structure changed, given the performative nature of the digital substrate used as their medium, presenting more elements, at the same time as reinforcing their semiotic indexical linking aspect. They are, today, our informational compasses.

Keywords: Index. SERP. Google. Search Engine.

1 Investigação fomentada pelo CNPq, por meio de Bolsa Produtividade em Pesquisa. Os colchetes duplos fazem ligação entre textos, na marcação semântica básica utilizada pela SemanticMediaWiki.

2 Doutora em Comunicação e Semiótica pela Pontifícia Universidade Católica de São Paulo, Brasil. Professor convidado da Universidade Estadual Paulista Júlio de Mesquita Filho, Brasil. Bolsista de Produtividade 2 CNPq. E-mail: gpciberespaco@gmail.com.

3 Doutora em Estudos da Linguagem pela Universidade Estadual de Londrina, Brasil. Docente da Universidade Estadual de Londrina, Brasil. E-mail: giraldes@uel.br. 


\section{INTRODUÇÃO}

Os índices, desde sua origem, estão ligados à existência de algo, até a sua acepção editorial e bibliográfica, percorreram uma trajetória que, de certa maneira, permaneceu pouco explorada por autores da área da Ciência da Informação. No entanto, devido ao seu alcance contemporâneo, capitaneado pragmaticamente pelos serviços de busca, percebeu-se a necessidade de resgatar, mesmo que de forma breve, a literatura para tecer algumas reflexões dessa trajetória e ao mesmo tempo compreender alguns aspectos de sua atual manifestação e até mesmo do seu sentido, por meio dos buscadores.

Os mecanismos de busca, sua categorização, a tipologia de seus índices, os aspectos relacionados às múltiplas sintaxes, a sistemas de recuperação, à Semiótica, à Semântica, enfim, todos esses temas foram, em certa medida, pesquisados sob a tutela da Ciência da Informação, conforme os temas se sucediam como o fio de Ariadne (MONTEIRO, 2009, 2017). Percebeu-se, portanto, a necessidade de produzir um texto sobre a essência do índice como fonte de referência na atualidade.

Notou-se que não havia investigação específica a respeito do tema, nas temáticas supracitadas, especialmente quando o índice do Google introduz o Mapa ou Grafo do Conhecimento (Knowledge Graph - KG), trazendo parte do conteúdo enciclopédico (não só, mas também) da Wikipédia. Naquele momento ocorreu uma hibridização entre índice e enciclopédia, alterando significativamente o primeiro em sua natureza e funcionalidade.

Wheatley, indexador britânico, em 1879, escreveu um ensaio com o título homônimo à questão supracitada, ou seja, What is an Index? No entanto, a investigação em tela volta-se para a página de resultados de um mecanismo de busca (Search Engine Results Page-SERP) do Google com 0 objetivo de avaliar o seu índice e discutir alguns elementos de sua estrutura que possam responder 0 questionamento: 0 que é um índice contemporâneo?

Como consequência, tentaremos esboçar alguns aspectos que englobem a questão conceitual e funcional dos índices na contemporaneidade. Assim, um fator relevante estudado, neste artigo, é a própria natureza dos índices contemporâneos, ou seja, como os resultados de busca vêm configurando-se.

\section{2 ÍNDICE: 0 QUE SIGNIFICA? A TRAJETÓRIA DA PALAVRA}

Ao contrário das enciclopédias, que possuem uma vasta literatura e exerce grande fascínio sobre os autores, os índices, mesmo com a emergência dos mecanismos de busca, não são comumente objeto de estudo, fato que reflete também na literatura existente sobre eles. São mais comuns na Economia, na Matemática, e mais recentemente na Computação por causa dos sistemas de recuperação 
da informação, mas não em grande medida, e hoje em razão dos serviços de busca, no entanto, como produto documentário ou obra de referência, a literatura é mais escassa. Em razão disso, suscitou curiosidade às pesquisadoras em tela em saber a origem, a história e a etimologia da palavra, para estudar seu status atual em uma SERP no Google.

Em artigo, Monteiro (2017) cita uma definição de Bentes sobre índices:

Os 'indexes' são uma espécie de discursos construídos ou pelos humanos ou através dos softwares informáticos. Conforme o sentido da palavra, os 'indexes' propõem-se a indicar ou apontar a direção que pode ser tomada como o objetivo de encontrar e ter acesso a informações. (BENTES, 2008, p. 22, Grifos da autora).

Ela menciona, inclusive, que a acepção de "index" não deve ser tomada no mesmo sentido de índice peirciano, pois, na concepção de Peirce, há uma relação causal com o objeto do mundo. Não obstante, estudando a etimologia e a pragmática da palavra, defendemos o sentido peirciano à concepção de índice, por alguns motivos explicitados.

Em primeiro lugar, na Semiótica, existem dois tipos de índices: os naturais (aos quais se refere Bentes) e os degenerados ou artificiais, de natureza simbólica, que fazemos aproximação à ordem de índices produzidos na Ciência da Informação e pelos mecanismos de busca, enfim, para todos os produtos documentários (MONTEIR0, 2006). No entanto, no estudo de Wellisch (1983), aquém ou além da origem da palavra, está a dimensão pragmática do índice, que também remete ao seu primeiro significado, conforme se verificará.

Em segundo lugar, Beare (2007, p. 257, tradução nossa) retrocede na História ao afirmar que as pinturas rupestres são os primeiros índices da humanidade "[...] - e as imagens são elas mesmas um índice." Observa a autora que nessas pinturas, assim como nas iluminuras de alguns manuscritos, aparecem dedos apontando (e mãos), indicando um fato, um trecho, não por acaso o dedo indicador (índex finger) é assim denominado por ser o dedo que aponta algo. "Peirce já chegou dizer que o índice age sobre o sistema nervoso.", como um dedo apontando algo (SANTAELLA, 2004, p.123).

Para Gomes e Gusmão (1983), a forma mais antiga de índice foi encontrada na armazenagem dos cuneiformes da Mesopotâmia, os documentos eram envoltos com uma cobertura sólida com a finalidade de preservá-los da falsificação e onde se registrava todas as informações necessárias a respeito do documento.

No entanto, para um verdadeiro índice ter existência, pelo menos como nós o entendemos, uma linguagem escrita precisava ser inventada e ser capaz de algum tipo de ordenação.

Em língua inglesa a grafia "index" é exatamente igual a forma latina e seu plural tanto pode ser como no latim oficial "índices" ou na forma anglicizada "indexes". Nos dicionários de língua inglesa, significa aquilo que aponta, dedo, apontador. 
A fim de aprofundar o estudo, Wellisch (1983) consulta dicionários latinos para verificar o significado de índice e constata que remete a qualquer tipo de indicador, sinal, token ou marcador; uma pessoa que revela ou aponta (a partir da qual desenvolveu o sentido de uma pessoa que trai um segredo, um informante e um homem que vigia); o título de um pergaminho, e daí o título de um livro; um simples resumo ou resumo de um livro ou seu índice; uma lista ou catálogo de livros e seus autores; e uma inscrição ou legenda.

Do ponto de vista gramatical, o autor afirma que a palavra (o substantivo) derivou do verbo dicare, que significa literalmente "mostrar". 0 prefixo iné usado para indicar direção de um ponto, uma direção a qual se aponta, originando o verbo indicare, que significa apontar, fazer conhecido, declarar, dar informações (WELLISCH,1983). Aqui também fica evidente como o índice provém de indicar, indicação, aproximando-se do sentido peirciano.

0 autor observa ainda que a forma latina procedeu do Grego, e por sua vez, das línguas indoeuropeias, sendo utilizada em vários países do continente europeu.

No sentido pragmático (ou aplicado) o substantivo e suas combinações e derivações, como "indexar", foram usados para vários dispositivos, métodos ou ferramentas que de uma forma ou de outra estão ligados ao básico conceito de mostrar ou apontar, como o índice de livros.

Wellisch (1983, p.149) cita que na Roma Antiga, Século I d.C., algumas obras de literatura tinham alguma identificação de título e às vezes de autor, "[...] um pedaço de pergaminho do qual são escritos os títulos que os gregos chamam "Syllabus." Depois os livros passaram a ter o título de índice (Sunt duo libelli diverso titulo,a Iteri "gladius", alteri "pugio" index erat) e depois de tabela de conteúdo ou lista de capítulo:

Aproximadamente na mesma época, no primeiro século d.C, o significado da palavra foi estendido de 'título' para um sumário ou uma lista de capítulos (às vezes com um breve resumo de seu conteúdo) e, portanto, para uma lista bibliográfica ou Catálogo. (WELLISCH,1983, p. 49, tradução nossa).

Em sua abordagem, Collison (1972, p.9) enfatiza que "A palavra índice, portanto, passou a incluir inúmeros sistemas de orientação que hoje não seriam designados como índices. Os índices às vezes eram uma lista de conteúdo, outras, um resumo, ou até mesmo várias notas."

No entanto, índices no sentido moderno, dando localizações exatas de nomes e assuntos em um livro, não foram compilados na Antiguidade, e apenas poucos índices daquela época parecem ter sido feitos antes da era da impressão. Há várias razões para isso. Primeiro, os livros escritos em forma de pergaminhos não tinham números de páginas ou de folhas nem de linhas. Além disso, mesmo havendo tais indicadores numéricos, teria sido impraticável acrescentar um índice no final da obra, pois para consultá-lo, o pergaminho teria que ser desenrolado até o final, não sendo prático o seu manuseio. 
Os livros começaram a ter certa ordenação interna no período medieval e principalmente no Renascimento, mas foi com o advento da impressão (1450) que a organização gráfica permitiu a compilação de índices, embora houvesse confusão entre o uso de índices e sumários.

Para a Associação Brasileira de Normas Técnicas, os índices são definidos como "Relação de palavras ou frases, ordenadas segundo determinado critério, que localiza e remete para as informações contidas num texto." (ABNT, 2004, p.1), no entanto, nos mecanismos de busca, como será discutido nas próximas seções, eles encontram-se em relação de contiguidade espacial com a informação, isto é, estão ligados ("linkados”): referência e informação em um continnum semiótico.

Após essa breve explanação, percebe-se que desde a sua origem o índice é aquilo que aponta e indica, o sentido referencial adotado no mundo bibliográfico condiz e funciona também como índice semiótico, na ordem da informação. Mas, além disso, nota-se que os índices (além de suas múltiplas sintaxes) estão mudando sua natureza de lista que aponta ou indica algo, para apresentar nessa, o conhecimento enciclopédico, além de outros agenciamentos sociotécnicos, conforme será abordado neste artigo.

\subsection{0 Î́ndice Sob a Perspectiva da Ciência da Informação}

Os índices na Ciência da Informação têm alcance bibliográfico, isto é, são um instrumento, fruto do processo de indexação, que visa sintetizar elementos de apresentação e localização de um texto, livro, item, informação e outros mais.

Arruda (2018) constata que o índice, para Conrad Gessner (percussor da bibliografia no Século $\mathrm{XVI}$ ), é um instrumento de planejamento e de controle patrimonial e bibliográfico. Nesse momento, considera-se que o índice ganha a acepção documentária 0 que 0 faz, de certa maneira, associá-lo às questões documentárias e apartá-lo de associações semióticas, na literatura especializada, embora em sua essência e natureza pragmática, nunca deixaram de ser signos indicadores de algo

0 índice é um recurso auxiliar imprescindível na busca de informação, é o elo entre o documento e o leitor, relação que se estabelece a partir da análise do documento e a representação condensada do assunto/ informação contido(a) no mesmo. De acordo com Gomes e Gusmão (1983, p.14) "0 índice, um tipo de sistema de recuperação da informação, atua como um filtro, seu objetivo é prover o usuário com documentos relevantes e bloquear a saída de documentos não relevantes."

Ainda de acordo com Arruda (2018), Gessner enfatizou as funcionalidades bibliográficas do índice, estabelecendo suas tipologias: 
a)apreender todas as palavras de um livro; b) propor apenas os assuntos de uma obra, todos ou os mais relevantes; a sinalização dos assuntos pode envolver e compreender parte das palavras, obviamente as mais significativas, contidas no texto; c) citar em uma única série os termos utilizados no texto e aqueles utilizados como descritores dos assuntos; d) distinguir, em listas ordenadas separadamente, os termos relativos a diferentes disciplinas; e) separar os vocabulários gregos dos latinos, ou reuni-los; f) acompanhar as entradas do índice com a indicação da folha ou número da página; em alguns casos, também especificando o número da linha ou conotando as diferentes partes da página mediante 0 uso de letras; g) dispor as referências, das entradas do índice, aos livros individuais e aos capítulos relativos da obra: para que, totalmente livres da paginação, sejam válidos para qualquer edição. (SERRAI, apud Arruda, 2018, p.19).

Silberger et al.(1990) definem índice como "[...] instrumento que dá acesso sistemático e metódico a todas as partes de uma ou mais unidades." (р. 93). As autoras distinguem os índices de livros dos índices de referências bibliográficas. Assim, existem vários tipos de acordo com 0 material indexado: índice de jornais; revistas; de formas literárias ou artísticas. E ainda: cumulativos; especializados; seletivos; exaustivos; anotados; analíticos e críticos.

Já a referida ABNT (2004) faz menção expressa aos índices dos documentos (no item “localização") e classifica-os quanto à ordenação: alfabéticos; sistemáticos; cronológicos; numéricos; alfanuméricos, e quanto ao enfoque: especial, quando organizado por: autores; assuntos; títulos; pessoas e/ou entidades; nomes geográficos; citações; anunciantes e matérias publicitária, e geral: quando combinadas duas ou mais categorias supracitadas.

A EISKO, Enciclopédia da ISKO (International Society for Knowledge Organization), classifica os índices em três conjuntos gerais de critérios: (1) critérios relacionados aos tipos e atributos dos documentos-fonte; (2) critérios relacionados aos atributos dos próprios índices; (3) critérios relacionados ao indexador, o processo de indexação, o contexto no qual a indexação está ocorrendo e as ferramentas utilizadas.

A literatura técnico-científica da área de Ciência da Informação aborda aspectos referentes à sua tipologia, critérios, classificação e ordenação, mas, antes de perscrutar o índice de um mecanismo de funcionamento algorítmico, denominado índice de busca, por Stäheli (2016), será necessário observar,

\section{o que é um índice.}

\section{PERCURSO METODOLÓGICO}

Pesquisar tecnologias ou serviços com alto grau de complexidade tecnológica não é uma tarefa confortável. Primeiro, porque o Google é uma empresa privada, segundo, porque se tem a sensação do paradigma da "caixa preta" (black box) 
isto é, como um fotógrafo que domina o input e o output da máquina, sem todavia conhecer ou dominar 0 que se passa no interior dela. (FELINTO; SANTAELLA, 2012). Assim também acontece ao inserir uma query na caixa de busca do Google (input) e visualizar a SERP ou índice de busca (output), nosso método: a análise documentária, mas nunca se sabe exatamente 0 acontece na parte de trás do mecanismo. Faz-se aproximação do objeto de pesquisa e mais do que uma análise representativa, ela é performativa. "Em lugar de representar a realidade, de buscar a sua verdade, empenha-se em investigar que resultados podem ser obtidos a partir de determinados inputs." (FELINTO; SANTAELLA, 2012, p. 60).

Então, mais do que explicar a realidade, a tarefa desta investigação é compreendê-la. A compreensão é ato inerente da pesquisa em Ciências Sociais e Humanas, conforme Alves (2003) aponta em suas ideias sobre a Lógica. A pesquisa, do ponto de vista do seu delineamento, é documental, ou seja, "[... e é aquela cujos objetivos ou hipóteses podem ser verificados através da análise de documentos bibliográficos ou não-bibliográficos." (CASTR0, 1977, p. 76).

Do ponto de vista do seu enfoque, a investigação é teórico-informal, pois parte de uma dúvida e não de uma tese a ser defendida dedutivamente, a saber: o que é um índice contemporâneo? Para tanto, buscou-se analisar e discutir o índice de busca a partir de uma SERP e à luz das ideias de Wheatley (1879).

De acordo com Wheatley $(1879$, p.7) 0 índice é "[...] um indicador da posição da informação requerida, como um poste de sinal em uma estrada, ou o dedo indicador da mão humana." Até aqui, temse uma concepção semiótica do índice. Mas Wheatley (1879) prossegue dizendo que o principal exemplo é um índice de livro, circunscrevendo-o no universo documentário. Ainda mais, qualquer entrada em um índice engloba pelo menos dois elementos: a palavra-chave e um número de páginas; e muitas vezes, mas não necessariamente para qualquer entrada, um bom índice apresenta referências cruzadas entre as diferentes entradas. As palavras-chave são ordenadas alfabeticamente para tornar o índice utilizável.

Essa é apenas a estrutura básica de um índice, no entanto, ajuda a compreender a sua natureza específica, pois de acordo com Stäheli (2016), o índice é de uma ordem epistêmica diferente dos textos indexados: é formalmente organizado (por alfabeto, não por importância-diferentemente dos ranqueamentos dos resultados de busca) e se baseia no isolamento de itens, como observado por Wheatley (1879).

A questão do isolamento ou do corte era importante para a discussão inicial da indexação, algo que a Semiótica poderia explicar. Assim, Gessner, no século 16, recomendou que "[...] é preciso escrever as entradas do índice separadamente para organizá-las na ordem desejada." (apudWEINBERG, 2010, p. 2283).

É importante notar que, dessa forma, a concepção de uma estrutura de documento de ordem diferente era e ainda é uma característica essencial do índice: "Um índice leva de uma ordem conhecida 
de símbolos a uma ordem desconhecida de informação. Um índice está em uma ordem diferente do documento ou coleção que fornece acesso." (WEINBERG, 2010 p. 2277). Vale observar que Stäheli (2016, p. 20) faz uma análise muito pertinente, evidenciando o índice como outro texto, um documento suplementar do texto original, elaborado por um indexador anônimo. Assim, "Os índices funcionam como máquinas de abstração e classificação, isolando os itens deste fluxo [das narrativas que indexam]."

Em linha teórica da Ciência da Informação, alguns elementos categoriais dos índices até podem ser observados no índice do Google, mas não com a mesma importância, posto que os corpora vão dinamicamente se apresentando nos resultados de acordo com a relevância e os critérios estabelecidos pelo mecanismo de busca.

Mas é importante observar a natureza epistêmica deles, isto é, sua natureza indicial de ligação (pois isto é mais significativo nos índices de busca, por causa dos links) posto que a ordem alfabética não se impõe como construto cognitivo de organização interna e muito menos a paginação; e a percepção que eles são também um texto auxiliar, partes moventes de outros documentos, fragmentos (snippets) de outros discursos, são portanto, índices sociais.

\section{MECANISMIOS DE BUSCA}

Atualmente os índices mais conhecidos são gerados algoritmicamente por máquinas mediante buscas realizadas em serviços denominados mecanismos de busca, que podem ser definidos como uma enorme base de dados de informações importantes a respeito de sites na Web. Sua aparição é relativamente recente, por volta da década de 90 (do século passado), se comparados à evolução histórica do índice, entretanto, sua evolução e importância fizeram deles um dos principais elementos da topografia do ciberespaço (MONTEIR0, 2007) e continuam com a mesma acepção, isto é, indicar ou apontar algo.

Monteiro et al. (2009) constatam que não há uma uniformização do termo na literatura e que eles são designados como máquinas de busca, motor de busca, serviços de busca, ferramentas de busca, buscadores e mecanismos de busca, este último, termo adotado na área da Ciência da Informação, conforme o Tesauro Brasileiro de Ciência da Informação, e significa "Programas de computador que realizam buscas para atender as consultas que Ihes são submetidas. Estes podem analisar as perguntas e/ou ranquear os resultados." (PINHEIRO; FERREZ, 2014, p. 248). 
0 fluxo livre de informação e a intenção da busca, como um dos fenômenos mais importantes das plataformas digitais (BATELLE, 2005), fizeram dos mecanismos um dos modelos de negócios mais rentáveis da economia. Nesse sentido, denominados como índices contemporâneos, por Monteiro (2017), esses sistemas de recuperação da informação trazem complexas e sofisticadas tecnologias e programas vindo a propiciar negociações do sentido para leitores de qualquer natureza. Operam por processos que incluem o rastreamento na Web, a indexação e a busca. Todos esses processos refletem outro momento histórico da evolução humana: a digitalização dos signos e a hibridização de homens, signos e máquinas.

Dessa forma, o objetivo do artigo em tela é prospectar o índice a partir da anatomia de uma SERP do Google e analisá-lo sob a perspectiva de sua estrutura (ou elementos) para tecer algumas considerações sobre o que é um índice contemporâneo, mediante, não só, mas também, de seus atributos enciclopédicos.

\subsection{Anatomia do índice contemporâneo: 0 google}

Embora Levy (2012) já tenha sido citado, por nós, em outras oportunidades (MONTEIR0, 2017), suas definições sobre o Google são muito oportunas e refletem o espírito "agressivo" e inovador da empresa, como "[...] uma máquina; um colecionador onívoro de informações”; "[...] um leiloeiro infalível”; "[...] um estudante de línguas, comportamentos e desejos assustadoramente hábil”; ainda, o Google é "[...] uma gigantesca máquina de aprendizagem baseada em inteligência artificial."

É fato que a busca, hoje, passa pela consulta dos índices gerados pelos buscadores, e em grande parte, pelo Google. De acordo com a Internet Live Stats, o Google respondeu mais de 5 bilhões pesquisas diárias (24 de fevereiro de 2019), 72.785 por segundo e demora 0,25 segundos para apresentar um resultado de busca. (INTERNET LIVE STATS, 2019). Friedman (2007, p. 211) afirma que "Nunca antes, na história do mundo, tanta gente - por conta própria - teve a possibilidade de encontrar tantas informações sobre tantas coisas e sobre tantas outras pessoas." (Grifos do autor).

No início do Google, os índices gerados tinham uma aparência mais textual, isto é, uma lista de resultados gerada a partir de uma consulta em ordem de pertinência, cujos valores só a referida empresa conhecia (e conhece). Com o passar do tempo, o índice incorporou elementos que constituem, até hoje, sua estrutura, conforme a Figura 01 ilustra. 
Figura 01 - The anatomy of a SERP (2010)

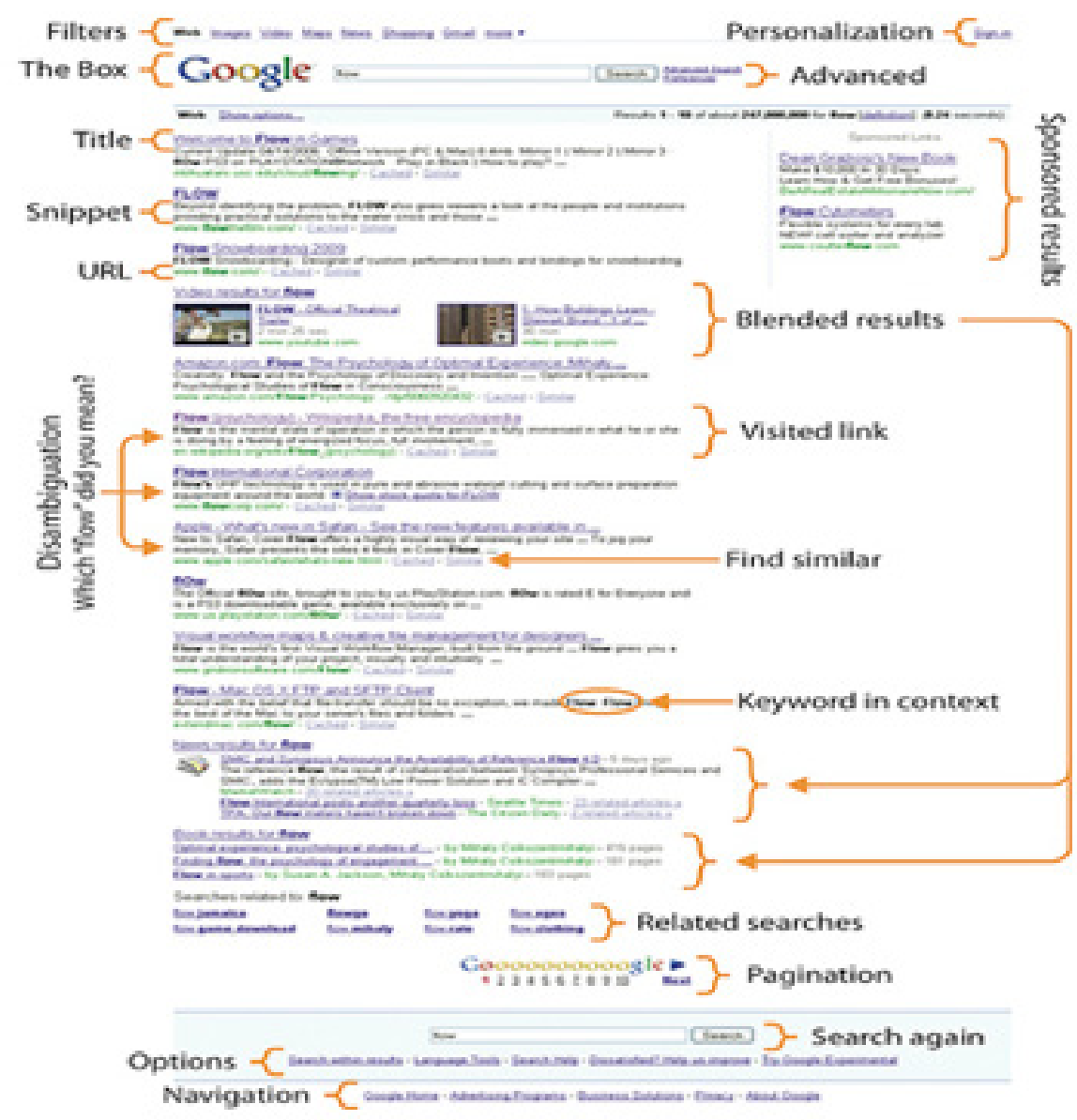

Fonte: Morville e Callender (2010, p. 32). Disponível em: $<$ http://www.flickr.com/photos/morville/4274260680/in/photostream/

Se é possível empregar a tipologia de índice apresentada na seção anterior, pode-se considerálo exaustivo, conforme Silberger et al. (1990, p. 95) pois "0 índice procura arrolar todas as publicações do assunto ou assuntos pretendidos." e geral, de acordo com a ABNT (2004), uma vez que combina vários enfoques. No entanto, a apresentação desse índice, de acordo com a SERP apresentada por Morville e Callender, em 2010, tem elementos inerentes, como: box da query (ou questão de pesquisa), filtros; pesquisa avançada; URL (Uniform Resource Locator) da página onde está apontando para 0 resultado; Título; resultados patrocinados (anúncios), snippet ou pequeno fragmento de texto junto ao título; elementos híbridos (blended results), desambiguação; marcação de link visitado; resultados semelhantes; pesquisas relacionadas; paginação do índice em tela; palavra-chave em contexto (não apresenta mais); buscar novamente (não aparece no layout de 2018, conforme Figura 02). 
Figura 02 - The anatomy of a SERP (2018)

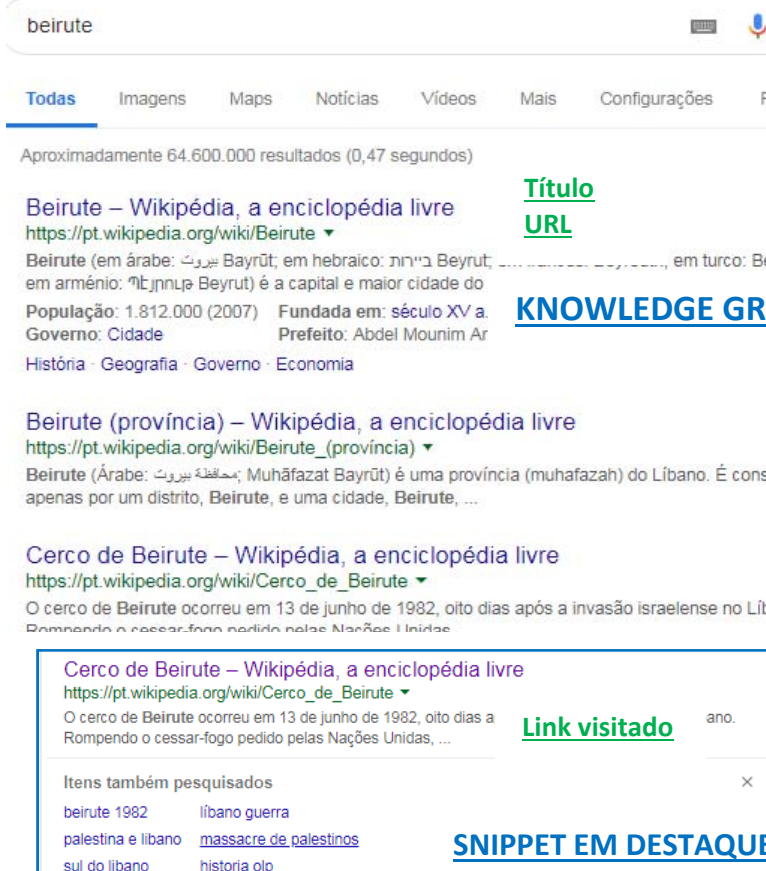

Turismo em Beirute: Com 71.501 dicas, avaliaçães e comentários, o TripAdvisor é o centro de informações para turismo em Beirute.

Os 10 melhores restaurantes: Beirute 2018 - TripAdvisor

https://www.tripadvisor.com.br , Oriente Médio , Líbano, Beirute v

Refeições: Beirute, Líbano: Veja 34.301 dicas e avaliações do TripAdvisol SNIPPET

Beirute e faça a busca por cozinha, preço, localização e mais.

2018: O que fazer em Beirute - OS 10 MELHORES .. - TripAdvisor

https://www.tripadvisor.com. br , ... , Libano , Beirute , $\mathrm{O}$ que fazer em Beirute -

Excursões em Beirute: Veja avaliações e fotos de 10 passeios turísticos em Beirute, Líbano no TripAdvisor.

2018: O que fazer em Beirute - OS 10 MELHORES ... - TripAdvisor https://www.tripadvisor.com.br , ... , Libano , Beirute , $\mathrm{O}$ que fazer em Beirute

Vida noturna em Beirute: Veja avaliações e fotos de 10 atrações da vida noturna em Beirute, Líbano no TripAdvisor.

Beirute renasce 12 anos depois da guerra | BBC Brasil | BBC World https://www.bbc.com/portuguese/cultura/020815_beirutecg.shtml -

Beirute renasce 12 anos depois da guerra - A capital do Líbano, Beirute, renasceu como um dos principais centros de entretenimento do mundo árabe, 12 anos

RESULTADOS ORGÂNICOS

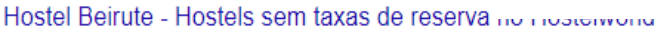

https://wnw brazilian hostelworld com 2 Libano Hostels , Beirute Hostels v

Temos 9 hostels em Beirute para mochileiros. Reservar um hostel ou um albergue em Beirute, sem

taxas, com base em 267 avaliações.

com.br/Attractions-g294005-Activities-c20-Beirut.htm

BOX

Filtros

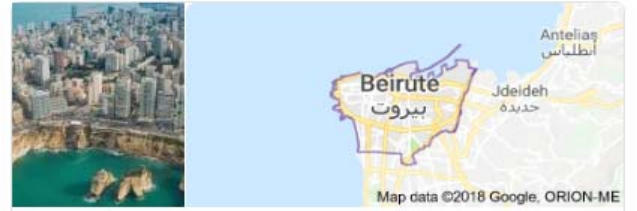

Beirute

Capital do Libano

KNOWLEDGE GRAPH

Beirute é a capital e maior cidade do Libano. Segundo estimativas de

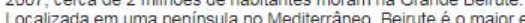
principal porto maritimo do país. Wikipédia

Área: $85 \mathrm{~km}^{2}$

Hora local: quarta-feira, $21: 25$

Tempo: $17^{\circ} \mathrm{C}$, vento $\mathrm{S}$ a $18 \mathrm{~km} / \mathrm{h}$, umidade de $64 \%$

Santo padroeiro: São Jorge

Código de área: +961 (01)

Planejar uma viagem

Cuia de viagem de Beirute

10. Hotel 3 estrelas com preço médio de RS 257 e 5 estrelas com preço médio de R\$ 546

1. Próximos eventos

Faculdades e universidades: Universidade Americana de Beirute, MAIS

Clubes e times: Ho RESULTADOS MISTURADOS

Pontos de interesse
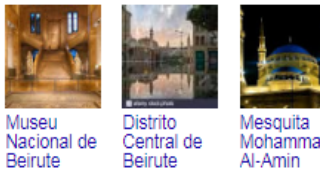

Mesquita

Mohamm
Al-Amin

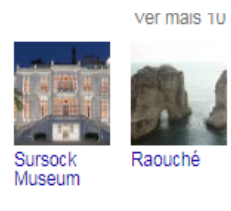

Itens também pesquisados

Ver mais 10

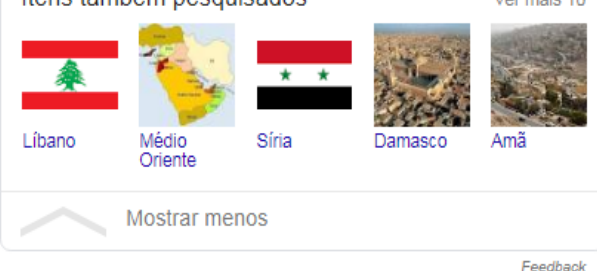

Pesquisas relacionadas a beirute

$\begin{array}{ll}\text { beirute cidade } & \text { beirute ingredientes } \\ \text { beirute onde fica } & \text { beirute receita } \\ \text { beirute comida } & \text { beirute médio oriente } \\ \text { beirute filme } & \text { beirute netflix }\end{array}$

Goooooooooogle >

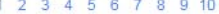

\section{PESQUISAS RELACIONADAS}

PAGINAÇÃO

Fonte: elaborado pelas autoras a partir da SERP do Google sobre Beirute capturada em 05 de dezembro de 2018. 
Com a implementação de novos recursos, a SERP foi alterando sua apresentação, trazendo mais elementos híbridos, como imagens, áudios, anúncios e também elementos enciclopédicos (leiase estruturados ou semantizados), trazidos da Wikipédia, conforme constam na Figura 02.

Diante do objetivo de conhecer a estrutura de um índice contemporâneo, a partir do Google ${ }^{4}$ que é gerado em uma SERP, buscou-se a análise de sua Anatomia, isto é, elementos constitutivos de sua estrutura, de acordo com Morville e Callender (2010) para responder a questão sobre o que é um índice. Vale destacar que o consta em verde ${ }^{5}$, sobrescrito na SERP, são os elementos já evidenciados em 2010 pelos autores supracitados. 0 que constam em azul são os elementos atualizados e importantes de inovação desse índice (VER FIGURA 02).

No item Box (Figura 02), há inovações de elementos híbridos para a busca, ou seja, além da linguagem verbal escrita, pode-se usar a linguagem verbal (voz) ou imagem (caso se acesse o Google Imagens). A palavra-chave, em vez de ser pré-determinada por um indexador, é agora denominada query (linguagem de busca), empregada por qualquer um que faça uma busca e a partir dela os índices são construídos. Interessante observar a característica dinâmica e movente da palavra-chave em relação aos textos que indicam e que propicia uma alta performatividade do índice.

Nos "filtros", conforme a Figura 02, encontram-se as "configurações" e "ferramentas" e fazem parte da pesquisada avançada e personalizada (esta última de forma deliberada ao selecionar preferências de busca, como idioma, período, país etc). Vale observar que a personalização sign in (Figura 01) hoje é automática, assim que ascende ao Google com a conta própria. A empresa utiliza dados do perfil e históricos de busca, localização etc para entregar resultados mais relevantes para 0 sujeito.

Nessa direção, o contexto e a localização acrescentam mais significado relevante às buscas, além da otimização semântica (relevância). Ambos, seja do ponto de vista linguístico (semântico) seja do ponto de vista pragmático (trilhas digitais deixadas pelo sujeito navegador), indicam a referência de mundo do pesquisador. Assim, a personalização reforça, cada vez mais (embora haja crítica em relação a ela (AFONSO et al., 2017), o caráter indicial do índice.

A partir desses pressupostos, Caldeira (2015) considera que o Google, ao oferecer a personalização e a contextualização do usuário, além de tecnologias da Web Semântica,

4 De acordo com Bostrom (2018), a ferramenta de busca do Google é, provavelmente, o maior sistema de Inteligência Artificial criado, por isso esse mecanismo foi utilizado como base para a nossa análise neste artigo.

5 Para impressão em P\&B, os elementos constitutivos de Morville e Callender (2010) são: Box, Filtro, Título, URL, link visitado, Snippet, resultados misturados (híbridos), pesquisas relacionadas e paginação do índice. 
[...] maximiza a relevância input (a consulta, a busca) para disponibilizar outputs (resultados do mecanismo de busca) que atendam à relevância de cada indivíduo, aumentando os efeitos cognitivos e diminuindo o esforço de processamento do usuário para que este alcance a meta que 0 levou à consulta. (p. 91, grifos da autora).

Tanto o box quanto a citação acima fazem lembrar do paradigma da "caixa preta", isto é, basta ao leitor aguardar os resultados que são apresentados no índice. Assim, a performatividade desse índice é um elemento importante à sua natureza, também as queries utilizadas pelos usuários constituem elementos sociais em um resultado de busca.

A estrutura do índice possui a localização do item no ciberespaço, isto é, a "URL", bem como o "título" e um pequeno trecho do texto indexado, o Snippet (fragmento), apresentado no índice; é a estrutura básica de apresentação. Então, lembrando Stäheli (2016), os índices são textos de outra natureza informacional, são compostos por alguns elementos de estrutura, mas são cortes de outros documentos, portanto, um texto auxiliar ou suplementar, agora não mais compilado por um indexador humano oculto, mas por algoritmos.

Comparando com a estrutura apresentada por Wheatley (1879), a palavra-chave é a query, a paginação é o URL, acessível por meio do link e a ordem alfabética é substituída por outros critérios, sendo o mais importante a relevância.

A novidade é o "snippet em destaque", denominação de Maksimava (2016) em que 0 trecho aparece com mais informações a respeito da questão de busca. Pode ser também rich snippet, quer dizer, texto em micro-formato com dados estruturados (Markup formats e RDFa) utilizado pelos serviços de busca, no caso o Google, para "[...] oferecer mais informações sobre uma página diretamente em sua listagem de resultados." (MARCEL, 2009). A expressão rich qualifica-o como "rico" a partir de inserção de imagens (estrelas de classificação ou fotos, em alguns resultados).

Os resultados orgânicos, embora não mencionados por Morville e Callender (2010), sempre existiram e podem fazer pares ordenados com resultados pagos, anúncios, que na Figura 01 aparecem como sponsored results, ou resultados patrocinados. Na Figura 02 nota-se que não aparece nenhum resultado sob a chancela "anúncio", mas apresenta resultados orgânicos que levam a sites patrocinados, como no caso de links para hotéis, sites especializados em viagens e hostels.

Vale observar que 0 artigo em tela não analisa o tipo de busca (que ficará para outra parte de análise dos índices contemporâneos) mas o fator indicial peirciano acentuado nesses índices (contexto, 
Iocalização, personalização) faz com que resultados com serviços locais apareçam cada vez mais, como hotéis, hostels, restaurantes, guias etc, orgânicos ou patrocinados.

Em blended results ou resultados misturados (híbridos) que aparecem na listagem na Figura 01, constam também no KG, na Figura 02. Em alguns casos aparecem no topo da listagem em forma de "caroussel", enfim, o que se enfatiza aqui é a hubridização dos índices, que reforça o paradigma semiótico, categorização apresentada por Monteiro para os mecanismos de busca (2013).

Um elemento novo, constante na Figura 02 e é o Knowledge Graph (KG), no lado direito do índice e também no primeiro resultado, lançado em 2012, nos Estados Unidos, pelo Google e dezembro de 2012, no Brasil. No Blog oficial do Google, ele é descrito como "[...] um enorme mapa de elementos do mundo real e as conexões entre eles, de modo a oferecer resultados mais relevantes." (GOOGLE, 2012). De acordo com a Wikipédia (G00GLE KNOWLEDGE GRAPH, 2018, grifo nosso) "O objetivo é fornecer aos usuários as informações necessárias para responder às suas dúvidas consultadas sem precisarem navegar para outros sites."

Apesar de não ser mais novidade, nem no mundo tecnológico nem para a sociedade, há algo nessa incorporação que modifica a natureza referencial do índice, isto é, ele não só aponta ou indica, mas ele traz a própria informação, tal qual uma enciclopédia.

Frisa-se que os fragmentos de conhecimento estão aparecendo no índice, seja por meio dos snippets ou por meio do KG, em proporções maiores tornando-o legível como texto, e contrariando, em certa medida, o fato que o índice.

Em contraste com um título ou um prefácio, o índice não é legível como tal - é um localizador de conhecimento. Eu quero chamar isso de dimensão operacional do índice, que entende 0 índice como um dispositivo para recuperação de informações. (STÄHELI, 2016, p.18).

Se por um lado o índice está se tornando legível, ele ainda não perde seu estatuto de texto suplementar, pois,

Essa ordem, baseada em itens isolados que podem ser organizados de diferentes maneiras, não constitui um texto próprio, mas é uma ordem 'auxiliar' que suplementa e altera (cf. Derrida, 1997) um texto já existente. Sua função reside, à primeira vista, na gestão eficiente dos dados existentes. (STÄHELI, 2016, p.18).

Apesar de 0 índice guardar a sua natureza mais precípua de localizador, já como texto suplementar de palavras-chave de documentos que indexam e indicam, tem investido em fragmentos de conhecimento, assemelhando-se às enciclopédias. Assim, como elas, o índice torna-se modelo semântico do saber e/ou do mundo (ECO, 2013) e apresenta: um título; uma imagem; uma descrição e um fato associado, conforme já apresentado no KG, na Figura 02. 
Em suma, comparando as Figuras 01 e 02 percebe-se a evolução do índice de busca nesse ínterim. 0 que mais se destaca, além da presença de imagens, é o fator enciclopédico, que se deve ao processo de semantização ou estruturação das bases de conhecimento, que reforça 0 atributo (semiótico) indicativo do índice pela grande presença de quesitos referenciais do mundo.

\section{CONSIDERAÇÕES FINAIS}

Os índices são fascinantes, mantêm a nossa relação com os objetos, indicam direções, posições e localizações. Os aplicativos e interfaces de dispositivos móveis são as bússolas informacionais da atualidade.

Da etimologia da palavra, de sua funcionalidade pragmática, passando pela acepção documentária, tudo leva em direção a sua natureza semiótica. Os índices falam ao sistema nervoso, ajudam na seleção da informação, na tomada de decisão e na diminuição da incerteza (ou deveriam).

De acordo com Stäheli (2016), a natureza epistêmica deles é diferente dos textos que indexam, ou seja, são cortes de outros documentos. Portanto, itens são incluídos ou excluídos, sendo possível assim investigar a natureza política dos índices e da indexação.

Já a sua estrutura básica, de acordo com Wheatley (1879) é: palavra-chave, paginação e ordem alfabética. Como observado na SERP, nesta pesquisa, a estrutura básica dos índices contemporâneos (ou de busca) é: URL, título e fragmento de texto (snippet). Além disso, a palavra-chave tornou-se linguagem de busca ou query, a paginação é a URL e, em vez da ordem alfabética como ordenação interna e cognitiva, são ordenados por critérios calcados, especialmente, na relevância, que pode ser interpretada como otimização semântica.

Ademais, se antes o índice não era legível como texto, dada a sua característica suplementar, hoje, mesmo mantendo a natureza de texto suplementar, em razão de sua enciclopedização, ele oferece informações fatuais em sua própria página, trazidas de verbetes da Wikipédia, permitindo inferir que sua natureza epistêmica está sofrendo alteração, assim como a sua estrutura básica.

Em síntese, como adequado em desfechos de pesquisa e ou artigos, respondemos a questão inicial de investigação. 0 que é um índice contemporâneo?

Um índice é um paratexto, cuja ordem epistêmica é diferente dos textos que indexam, mas apresentam, cada vez mais, fragmentos maiores de conhecimento em seu corpo. Possuem uma estrutura básica que se alterou com a evolução das mídias que os suportam. Hoje, apresentam um 
número maior de elementos, apesar de sua estrutura básica ser composta de título, URL e snippet (fragmento) e são organizados por critérios de relevância (o principal) entre outros estabelecidos pelos proprietários dos serviços de busca. Entretanto, dois aspectos da funcionalidade permanecem: primeiro, sua natureza pragmática e semiótica de indicar, apontar e mostrar; segundo, eles ainda são poderosos instrumentos de organização do conhecimento. Nessa direção, de acordo com Stäheli (2016), o funcionamento imanente do índice é a sua capacidade de sugerir e produzir links.

Dessa maneira, esse artigo pretendeu atualizar o que é um índice, a partir do importante ensaio de Wheatley, de 1879, sob a perspectiva de um índice digital, dinâmico, movente, performativo e híbrido. Agenciamentos sociotécnicos respondem hoje pelos índices contemporâneos.

\section{AGRADECIMENTOS}

Ao CNPq pelo fomento concedido à pesquisa, por meio da Bolsa Produtividade em Pesquisa.

\section{REFERÊNCIAS}

AFONSO, Elaine Parra; MONTEIR0, Silvana Drumond; VIDOTTI, Silvana A. B. Gregório; SANT’ANA, Ricardo C. Gonçalves. Os mecanismos de busca e as implicações nos aspectos de privacidade. RICI. Revista Ibero-Americana de Ciência da Informação, v. 10. n. 2, 422-442, 2017.

ALVES, Alaôr Caffé. Lógica: pensamento formal e argumentação. 3.ed. São Paulo: Quartier Latin, 2003.

ARRUDA, André Vieira de F. De indicibus librorum e a arte da indicialização em Conrad Gesner (parte i1): contexto e princípios. Inf. Inf., Londrina, v. 23, n. 2, p. 14 - 37, maio/ago. 2018.

ASSOCIAÇÃO BRASILEIRA DE NORMAS TÉCNICAS. NBR $\mathbf{6 0 3 4}$ - Índice - apresentação. 2. ed. Rio de Janeiro, 2004.

BATTELLE, J. A busca: como o Google e seus competidores reinventaram os negócios e estão transformando nossas vidas. Rio de Janeiro: Elsevier, 2005.

BEARE, Geraldine. Past, presente and future. The Indexer, v. 25, n. 4, p. 257-264, October 2007.

BENTES, V. P. A contribuição peirciana para a representação indexal de imagens visuais.

Encontros Bibli: Revista Eletrônica de Biblioteconomia e Ciência da Informação, n. 25, p.

15-35, 2008. Disponível em: <https://periodicos.ufsc.br/index.php/eb/article/view/15182924.2008v13n25p15/878>. Acesso em: 2 fev. 2016.

BOSTROM, Nick. Superinteligência: caminhos, perigos e estratégias para o novo humano. Rio de Janeiro: Dark Side, 2018. 
CASTR0, Cláudio de Moura. A prática da pesquisa. São Paulo: McGraw-Hill, 1977.

CALDEIRA, F. H. 0 mecanismo de busca do Google e a relevância na relação sistema-usuário.

Letrônica: Revista digital do Programa de Pós-Graduação em Letras PUCRS. Disponível em: <http:// revistaseletronicas.pucrs.br/ojs/index.php/letronica/article/view/19616> . Acesso em: 12 de jun. 2016.

COLLISON, Robert L. Índices e indexação: guia para indexação de livros e coleções de livros, periódicos, partituras musicais, discos, filmes e outros materiais. São Paulo: Polígono, 1972. 223p.

ECO, Umberto. Da árvore ao labirinto: estudos históricos sobre o signo e a interpretação. Rio de Janeiro: Record, 2013.

FELINTO, Erick; SANTAELLA, Lúcia. 0 explorador de abismos: Vilém Flusser e o pós-humanismo. São Paulo: Paulus, 2012.

FRIEDMAN, Thomas L. 0 mundo é plano: uma breve história do século XXI. Rio de Janeiro: Objetiva, 2007.

GOMES, Hagar Espanha; GUSMÃO, Heloisa Rios. Guia prático para a elaboração de índice. Niterói: Grupo de Bibliotecários em Informação e Documentação em Ciências Sociais e Humanas da APB-RJ, 1983. 68 p.

G00GLE Knowledge Graph. Wikipédia. Disponível em: <https://pt.wikipedia.org/wiki/Google_ Knowledge_Graph>. Acesso em 20 dez. 2018.

G00GLE. The Knowledge Graph. Disponível em: <https://www.blog.google/products/search/ introducing-knowledge-graph-things-not/> . Acesso em: 20 dez. 2018.

INTERNET LIVE STATS. Google search today. Disponível em: <http://www.internetlivestats.com/totalnumber-of-websites/>. Acesso em: 20 set. 2018.

LEVY, S. Google: a biografia. Como o Google pensa, trabalha e molda nossas vidas. São Paulo: Universo dos Livros, 2012.

MAKSIMAVA, Masha. Google Search Results Type: a visual guide. Disponível em: <https://www.linkassistant.com/news/serp-guide.html >. Acesso em: 08 mar. 2017.

MARCEL, Frank. Rich Snippets - mais informação na Snippet do Google. 2009. Disponível em: < http://www.agenciamestre.com/marketing-digital/rich-snippets-mais-informacao-snippet-google/ >. Acesso em: 11 fev. 2018.

MONTEIRO, Silvana Drumond. 0 Ciberespaço: 0 termo, a definição e o conceito. DataGramaZero, v. 8, p. 1-18, 2007.

MONTEIR0, Silvana Drumond. A relação das enciclopédias com os índices e a Web Semântica: linhas de força para a organização e significação na pós-modernidade. Transinformação, v. 29, n. 1, p. 1525, jan./abr. 2017. 
MONTEIRO, Silvana Drumond. Semiótica peirciana e a questão da informação e do conhecimento. Encontros Biblos. Revista de Biblioteconomia e Documentação, v. 11, n. esp. 3, p. 43-57, 2006.

MONTEIRO, Silvana Drumond et al. As categorias dos mecanismos de busca: objeto em construção e em permanente modificação. SEMINÁRIO EM CIÊNCIA DA INFORMAÇÃO, III, 2009, Londrina. Anais... Londrina: Dep. Ciência da Informação, 2009. p. 1-20.

MONTEIR0, Silvana Drumond et al. A tradução intersemiótica dos mecanismos de busca no ciberespaço. Informação \& Informação, Londrina, v. 18, n. 2, p. 37-59, maio/ago. 2013

MORVILLE, Peter; CALLENDER, Jeffery. Search patterns: design for discovery. Canadá: O’Reilly, 2010.

PINHEIRO, Lena Vânia Ribeiro; FERREZ, Helena Dodd. Tesauro Brasileiro de Ciência da Informação. Rio de Janeiro: IBICT, 2014.

SANTAELLA, Lucia. A teoria geral dos signos: como as linguagens significam as coisas. São Paulo: Pioneira, 2004.

SILBERGER, Kathryn Kemp; Obras de referência: subsídios para uma avaliação criteriosa. Florianópolis: Ed. UFSC, 1990.

STÄHELI, Urs. The politics of invibility. D. Society and Space, v. 34, n. 1, 14-29, 2016.

WEINBERG, Bella Hass . Indexing: history and theory. In: BATES, Marcia J.; MAACK, Mary Niles (eds). Encyclopedia of Library and Information Sciences. Boca Raton: CRC Pres. p, 2277-2290.

WELLISCH, Hans H. 'Index': the word, its history, meanings and usages. The Indexer, v. 13, n. 3, p. 147-151, April 1983.

WHEATLEY, Henry B. What is an index? A few notes on indexes and indexers. London: Longmans, Green \& Co., 1879. (Fac Símile for the Index Society, 2002). 